\title{
Individually customised fetal weight charts derived from ultrasound measurements: the Generation R Study
}

\author{
Romy Gaillard • Maria A. J. de Ridder • Bero O. Verburg • \\ Jacqueline C. M. Witteman · Johan P. Mackenbach · Henriëtte A. Moll • \\ Albert Hofman · Eric A. P. Steegers • Vincent W. V. Jaddoe
}

Received: 13 June 2011/Accepted: 31 October 2011/Published online: 15 November 2011

(C) The Author(s) 2011. This article is published with open access at Springerlink.com

\begin{abstract}
Maternal and fetal characteristics are important determinants of fetal growth potential, and should ideally be taken into consideration when evaluating fetal growth variation. We developed a model for individually customised growth charts for estimated fetal weight, which takes into account physiological maternal and fetal characteristics known at the start of pregnancy. We used fetal ultrasound data of 8,162 pregnant women participating in
\end{abstract}

Electronic supplementary material The online version of this article (doi:10.1007/s10654-011-9629-7) contains supplementary material, which is available to authorized users.

R. Gaillard · V. W. V. Jaddoe $(\bowtie)$

The Generation R Study Group (AE006), Erasmus Medical Center, P.O. Box 2040, 3000 CA Rotterdam, The Netherlands

e-mail: v.jaddoe@erasmusmc.nl

R. Gaillard - J. C. M. Witteman · A. Hofman - V. W. V. Jaddoe Department of Epidemiology, Erasmus Medical Center,

Rotterdam, The Netherlands

R. Gaillard · H. A. Moll · V. W. V. Jaddoe

Department of Paediatrics, Erasmus Medical Center, Rotterdam,

The Netherlands

M. A. J. de Ridder

Department of Biostatistics, Erasmus Medical Center,

Rotterdam, The Netherlands

M. A. J. de Ridder

Dutch Growth Foundation, Rotterdam, The Netherlands

B. O. Verburg · E. A. P. Steegers

Department of Obstetrics and Gynaecology, Erasmus Medical

Center, Rotterdam, The Netherlands

J. P. Mackenbach

Department of Public Health, Erasmus Medical Center,

Rotterdam, The Netherlands the Generation R Study, a prospective, population-based cohort study from early pregnancy onwards. A repeated measurements regression model was constructed, using backward selection procedures for identifying relevant maternal and fetal characteristics. The final model for estimating expected fetal weight included gestational age, fetal sex, parity, ethnicity, maternal age, height and weight. Using this model, we developed individually customised growth charts, and their corresponding standard deviations, for fetal weight from 18 weeks onwards. Of the total of 495 fetuses who were classified as small size for gestational age $(<10$ th percentile) when fetal weight was evaluated using the normal population growth chart, $80(16 \%)$ were in the normal range when individually customised growth charts were used. 550 fetuses were classified as small size for gestational age using individually customised growth charts, and 135 of them (25\%) were classified as normal if the unadjusted reference chart was used. In conclusion, this is the first study using ultrasound measurements in a large population-based study to fit a model to construct individually customised growth charts, taking into account physiological maternal and fetal characteristics. These charts might be useful for use in epidemiological studies and in clinical practice.

Keywords Customised fetal growth curves - Ultrasound · Fetal weight - Biometry · Ethnicity .

Maternal anthropometrics

\section{Introduction}

Early and accurate detection of fetal growth failure is important for prenatal and early postnatal care [1, 2]. Small size for gestational age fetuses are at increased risk of 
perinatal morbidity and mortality. It has also been suggested that fetal growth restriction is associated with cardiovascular and metabolic disease in later life [3, 4].

In clinical practice, fetal growth is evaluated using standard population reference tables for fetal biometry measurements [5]. These standard reference growth charts neglect the normal variation in fetal growth potential and size, due to several physiological maternal and fetal characteristics, which can be considered as determinants of non-pathological fetal growth variation [6-11]. This might lead to misclassification of fetuses with pathological growth abnormalities. By adjusting the standard growth charts for physiological characteristics, individually customised fetal growth charts can be developed [12]. These customised fetal charts may give an indication of the fetal growth potential by estimating the expected fetal size, and might improve the distinction between physiological and pathological growth variation [13]. A previous strategy to develop customised fetal growth charts was based on the influence of maternal and fetal physiological characteristics on birth weight and did not take into consideration that the influence of maternal and fetal characteristics on fetal growth might vary during pregnancy [12].

Therefore, using data from 8,162 pregnant women participating in a prospective, population-based cohort study from early pregnancy onwards, we constructed individually customised growth charts taking into account non-pathological maternal and fetal characteristics.

\section{Methods}

\section{Design}

This study was embedded in the Generation R Study, a population-based prospective cohort study from early pregnancy onwards in Rotterdam, the Netherlands [14]. The study has been approved by the Medical Ethical Committee of the Erasmus Medical Center in Rotterdam (MEC 198.782/2001/31). Written consent was obtained from all participating women [15]. All pregnant women were enrolled between 2001 and 2005. Response rate at birth was $61 \%$. Assessments during pregnancy were planned in first, second and third trimester. The individual timing of these assessments depended on the gestational age at enrolment. Fetal growth was measured in second and third trimester. The median gestational age of the measurement in second trimester was 20.5 weeks (95\% range: $18.5,23.2)$. Of these second trimester measurements, $29 \%$ were before 20 weeks of gestation, $59 \%$ were between 20 and 22 weeks of gestation, and $12 \%$ were after 22 weeks of gestation. The median gestational age of the measurement in third trimester was 30.3 weeks (95\% range: $28.4,32.9$ ).
Of these third trimester measurements, $32 \%$ were before 30 weeks of gestation, $61 \%$ were between 30 and 32 weeks of gestation, and $7 \%$ were after 32 weeks of gestation.

In total, 8,880 women were enrolled during pregnancy. First, we excluded women who were enrolled in the study after the 24th week of gestation, because of the difficulty of pregnancy dating, and women in which ultrasound observations were not completely available making calculation of estimated fetal weight impossible. Second, we excluded multiple pregnancies, and pregnancies leading to major fetal anomalies, termination of the pregnancy, and fetal death. The cohort for analysis comprised 8,162 pregnant women with 16,018 estimated fetal weight observations. For the final multivariate model, there were 5,473 subjects with complete data on all maternal and fetal characteristics (Online Resource 1, Figure S1).

\section{Fetal ultrasound measurements}

Ultrasound exams were performed using an Aloka ${ }^{\circledR}$ Model SSD-1700 (Tokyo, Japan) or the ATL-Philips ${ }^{\circledR}$ Model HDI 5000 (Seattle, Washington, USA) equipped with a 5.0 MHz, high frequency curved array transducer. Ultrasound examinations were carried out in a research setting at a regional health facility in each trimester. As establishing gestational age with fetal ultrasound examinations is the most accurate method for pregnancy dating [16-18], dating of the pregnancy was performed using the first ultrasound measurement of crown-rump length (CRL) or biparietal diameter (BPD), using dating curves derived from this cohort [5]. Standardised ultrasound planes for head circumference, abdominal circumference, and femur length were used [19-21]. Estimated fetal weight was calculated using the formula of Hadlock with parameters head circumference (HC), abdominal circumference (AC) and femur length (FL) in $\mathrm{cm}$ : estimated fetal weight $=$ $10 \times(1.326-0.00326 \times \mathrm{AC} \times \mathrm{FL}+0.0107 \times \mathrm{HC}+$ $0.0438 \times \mathrm{AC}+0.158 \times \mathrm{FL})$ [22]. The time period was restricted to gestational age of 18 weeks (earliest reliable estimated fetal weight) to 36 weeks. Visits for ultrasonography after 36 weeks were excluded as in this cohort they were probably performed because of suspected pathology.

Physiological maternal and fetal characteristics

Maternal age (age groups: $\leq 27$ years, $28-32$ years, $\geq 33$ years), and height were registered at the first prenatal visit. Information about previous pregnancies (gravidity; parity), pre-pregnancy weight of the mother, and ethnicity was obtained by questionnaire at enrolment. The response rate for this questionnaire was $91 \%$. Ethnicity of mothers was defined according to the classification of Statistics Netherlands [23], using country of birth of her parents. 
Mothers with Moroccan or Surinamese background were asked about their ethnic origin and further classified as Surinamese-Hindustani, Surinamese-Creole, MoroccanArabic or Moroccan-Berber. The pathological determinant maternal smoking was also used because it has a substantial effect on fetal growth and leads to a more accurate regression model $[24,25]$. For the construction of a customised growth chart, the term for smoking should be set to zero, whether the pregnant woman smokes or not. Hereby non-smoking is used as reference category.

\section{Statistical analyses}

First an unadjusted reference curve for estimated fetal weight was constructed by modelling the relation between gestational age and estimated fetal weight, using repeated measurement analysis and fractional polynomials [26]. The effect of each physiological maternal and fetal characteristics was estimated separately by adding the main term and its interaction with gestational age to the model. This interaction term allows for a change in effect size during pregnancy. If the interaction term was significant $(P<0.05)$ it was tested whether adding the interaction with square of gestational age was significant. If the interaction term was not significant, it was removed from the model. Subsequently, we included these characteristics in the multivariate model using backward selection. To examine the effects of the physiological maternal and fetal characteristics on estimated fetal weight, we computed, from the one-characteristic and multivariate model, estimated differences in estimated fetal weight at gestational ages of 20 and 30 weeks, and differences in birth weight of neonates born after a gestation of 36 weeks or more. Second, we constructed individually customised fetal growth charts using the multivariate model, including the individual maternal and fetal characteristics. The expected mean value and standard deviation of estimated fetal weight at a certain gestational age can be computed using these models. Third, we used the first observation of fetal weight after 27 weeks of gestation, to compare the classification of fetal weights based on population growth chart and the individually customised fetal growth charts. For all analyses SAS 8.2 (SAS Institute Inc., Cary, NC, USA) was used.

\section{Results}

Subject characteristics

Table 1 shows the characteristics of mothers and children. At 20, 28 and 36 weeks of gestation mean fetal weight was
Table 1 Subject characteristics $(\mathrm{N}=8,162)$

\begin{tabular}{ll}
\hline & $\begin{array}{l}\text { Median (90\% range) } \\
\text { or percentage }\end{array}$ \\
\hline Maternal characteristics & \\
Age (years) & $30.3(20.4 ; 37.8)$ \\
Height (cm) & $167(155 ; 180)$ \\
Pre-pregnancy weight $(\mathrm{kg})$ & $64(50 ; 91)$ \\
Ethnicity $(\%)$ & \\
Dutch & $59.4 \%$ \\
Other European & $5.9 \%$ \\
Dutch Antilles & $2.4 \%$ \\
Cape Verdian & $3.5 \%$ \\
Moroccan-Arabic & $1.9 \%$ \\
Moroccan-Berber & $3.7 \%$ \\
Surinamese-Creole & $3.2 \%$ \\
Surinamese-Hindustani & $3.4 \%$ \\
Turkish & $8.0 \%$ \\
Others & $8.6 \%$ \\
Primigravida (\%) & $43.4 \%$ \\
Nullipara (\%) & $56.6 \%$ \\
Maternal smoking during pregnancy (\%) & $17.0 \%$ \\
Child characteristics & \\
Male (\%) & $50.4 \%$ \\
\hline
\end{tabular}

326, 1,201 and 2,568 g, respectively. Mean birth weight was $3,443 \mathrm{~g}$ (Table 2).

Maternal and fetal characteristics and estimated fetal weight

Figure 1 gives the full multivariate repeated regression model which enables construction of individually customised fetal growth charts. All maternal and fetal characteristics had a significant contribution to the model and all interaction terms with gestational age were significant. For parity and maternal weight, the interaction terms with gestational age squared were significant. The exact formula and coefficients of the multivariate model are given in Fig. 1.

Table 3 gives the associations of the maternal and fetal characteristics with estimated fetal weight derived from the multivariate model. At a gestational age of 20 weeks, no significant differences were found. At a gestational age of 30 weeks, the difference between male and female estimated fetal weight, was $15 \mathrm{~g}(95 \% \mathrm{CI}: 10,22)$ and between first-borns and others $16 \mathrm{~g}$ (95\% CI: 9, 29). As compared to children of Dutch mothers, children of mothers of CapeVerdian, Surinamese-Creole and Surinamese-Hindustani ethnicity had a lower estimated fetal weight at 30 weeks of gestation. The fetuses of mothers of older age were heavier 
Table 2 Distribution of estimated fetal weight and birth weight $(\mathrm{N}=8,162)$

\begin{tabular}{llcccc}
\hline & Gestational age (weeks) & Mean $(\mathrm{g})$ & Standard deviation $(\mathrm{g})$ & Coefficient of variation $(\%)$ & $90 \%$ reference interval \\
\hline Estimated fetal weight $^{\mathrm{a}}$ & 20 & 326 & 29 & 9.1 & $(277 ; 374)$ \\
& 28 & 1,201 & 124 & 10.3 & $(998 ; 1,405)$ \\
& 36 & 2,568 & 291 & 11.3 & $(2,091 ; 3,046)$ \\
Birth weight $^{\mathrm{b}}$ & 40 & 3,443 & 447 & 13.0 & $(2,710 ; 4,176)$ \\
\hline
\end{tabular}

a The unadjusted reference for estimated fetal weight is described by: mean estimated fetal weight $=13,735-5.4340 \times 10^{7} \times \mathrm{GA}^{-2}+$ $4.2970 \times 10^{7} \times \mathrm{GA}^{-2} \times \log (\mathrm{GA})-0.88865 \times 10^{7} \times \mathrm{GA}^{-2} \times(\log (\mathrm{GA}))^{2}$

Standard deviation for estimated fetal weight $=-24.659+0.00677 \times \mathrm{GA}^{3}$

b The unadjusted equation for birth weight, between a gestational age of $36-44$ weeks, is described by: mean birth weight $=3,443+$ $178 \times(\mathrm{GA}-40)$

Fig. 1 Formula for estimated fetal weight for individually customised growth charts

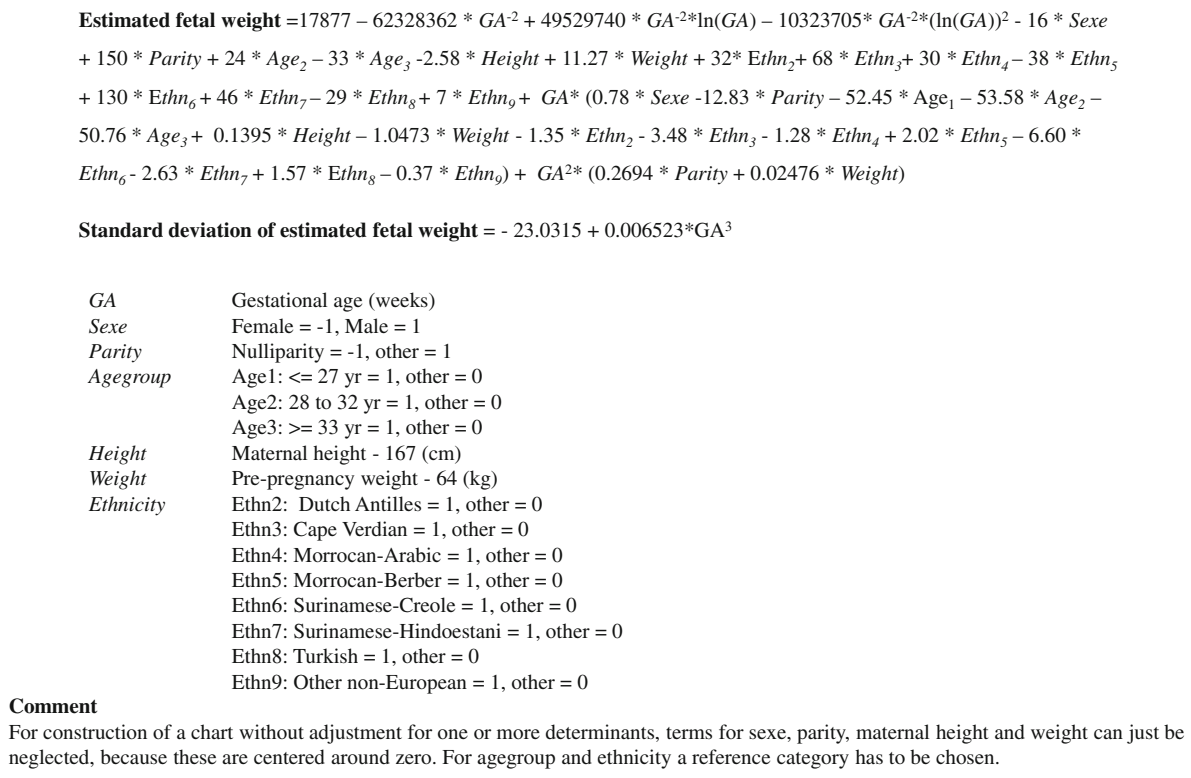

as compared to mothers aged younger than 27 years. Estimated fetal weight increased with $16 \mathrm{~g}$ (95\% CI: 11 , 21) per $10 \mathrm{~cm}$ increase in maternal height and with $21 \mathrm{~g}$ (95\% CI: 19, 24) per $10 \mathrm{~kg}$ increase in maternal weight. Birth weight was significantly influenced by fetal sex, parity, ethnicity, maternal height and maternal weight (all $P$-values $<0.05$ ), but not by maternal age. Results from the one characteristic models are given in the Online Resource 1, Table S1.

\section{Customised fetal growth charts}

Using the multivariate model, we constructed customised fetal growth charts for all participants in our study, by filling in the individual maternal and fetal characteristics in the regression equation in Fig. 1, Online Resource 2 Excel sheet. As illustration, Fig. 2 shows the expected estimated fetal growth for 3 different children, with different maternal and fetal characteristics. Figure 3 shows that of the total of 495 fetuses who were classified as small size for gestational age $(<10$ th percentile) when fetal weight was evaluated using the normal population growth chart, 80 (16\%) were in the normal range when individually customised growth charts were used. 550 fetuses were classified as small size for gestational age using individually customised growth charts, and 135 of them (25\%) were classified as normal if the unadjusted reference was used.

\section{Discussion}

We developed a model to construct individually customised fetal growth charts, taking physiological or nonpathological maternal and fetal characteristics and their increasing effect during pregnancy into consideration. With these customised growth charts, fetal size can be evaluated taking the normal variation in fetal growth potential into account. 
Table 3 Associations of non-pathological determinants with mean estimated fetal weight and with mean birth weight using multivariate regression analysis $(\mathrm{N}=5,473)$

\begin{tabular}{|c|c|c|c|c|c|c|c|c|c|}
\hline & \multicolumn{6}{|c|}{ Differences $(\mathrm{g})$ in estimated fetal weight } & \multirow{2}{*}{\multicolumn{3}{|c|}{$\frac{\text { Differences }(\mathrm{g}) \text { in birth weight }}{40 \text { weeks of gestation }}$}} \\
\hline & \multicolumn{3}{|c|}{20 weeks of gestation } & \multicolumn{3}{|c|}{30 weeks of gestation } & & & \\
\hline & $\begin{array}{l}\text { Difference } \\
(\mathrm{g})\end{array}$ & $95 \% \mathrm{CI}$ & $P$-value & $\begin{array}{l}\text { Difference } \\
(\mathrm{g})\end{array}$ & $95 \% \mathrm{CI}$ & $P$-value & $\begin{array}{l}\text { Difference } \\
(\mathrm{g})\end{array}$ & $95 \% \mathrm{CI}$ & $P$-value \\
\hline Gender fetus (male-female) & 0 & $(-7 ; 7)$ & 0.98 & 15 & $(10 ; 22)$ & $<0.0001$ & 112 & $(90 ; 134)$ & $<0.0001$ \\
\hline $\begin{array}{c}\text { Parity (para } 1 \text { or } \\
\text { more-para } 0 \text { ) }\end{array}$ & 3 & $(-5 ; 10)$ & 0.46 & 16 & $(9 ; 229)$ & $<0.0001$ & 176 & $(153 ; 200)$ & $<0.0001$ \\
\hline \multicolumn{10}{|l|}{ Ethnicity } \\
\hline Dutch and other European & \multicolumn{3}{|l|}{ Reference } & \multicolumn{3}{|l|}{ Reference } & \multicolumn{3}{|l|}{ Reference } \\
\hline Dutch Antilles & 5 & $(-18 ; 28)$ & 0.69 & -9 & $(-30 ; 13)$ & 0.43 & -92 & $(-170 ;-14)$ & 0.02 \\
\hline CapeVerdian & -2 & $(-20 ; 17)$ & 0.87 & -36 & $(-54 ;-19)$ & $<0.0001$ & -117 & $(-180 ;-55)$ & 0.0002 \\
\hline Moroccan-Arabic & 5 & $(-23 ; 32)$ & 0.75 & -8 & $(-33 ; 17)$ & 0.52 & -33 & $(-124 ; 58)$ & 0.48 \\
\hline Moroccan-Berber & 3 & $(-17 ; 23)$ & 0.79 & 23 & $(5 ; 41)$ & 0.01 & 15 & $(-49 ; 80)$ & 0.65 \\
\hline Surinamese-Creole & -2 & $(-22 ; 18)$ & 0.84 & -68 & $(-87 ;-49)$ & $<0.0001$ & -161 & $(-228 ;-94)$ & $<0.0001$ \\
\hline Surinamese-Hindustani & -6 & $(-26 ; 14)$ & 0.54 & -33 & $(-51 ;-14)$ & 0.0006 & -163 & $(-230 ;-97)$ & $<0.0001$ \\
\hline Turkish & 2 & $(-12 ; 16)$ & 0.75 & 18 & $(5 ; 31)$ & 0.007 & 30 & $(-17 ; 76)$ & 0.21 \\
\hline Other & 0 & $(-14 ; 13)$ & 0.95 & -4 & $(-16 ; 8)$ & 0.51 & 38 & $(-6 ; 83)$ & 0.09 \\
\hline \multicolumn{10}{|l|}{ Maternal age } \\
\hline$\leq 27$ years & \multicolumn{3}{|l|}{ Reference } & \multicolumn{3}{|l|}{ Reference } & \multicolumn{3}{|l|}{ Reference } \\
\hline 28-32 years & -2 & $(-10 ; 7)$ & 0.67 & 10 & $(2 ; 17)$ & 0.02 & 1 & $(-27 ; 30)$ & 0.93 \\
\hline$\geq 33$ years & -1 & $(-10 ; 9)$ & 0.89 & 28 & $(19 ; 36)$ & $<0.0001$ & 12 & $(-19 ; 43)$ & 0.45 \\
\hline Maternal height $(10 \mathrm{~cm})$ & 2 & $(-3 ; 8)$ & 0.45 & 16 & $(11 ; 21)$ & $<0.0001$ & 101 & $(82 ; 119)$ & $<0.0001$ \\
\hline Maternal weight $(10 \mathrm{~kg})$ & 2 & $(-1 ; 5)$ & 0.34 & 21 & $(19 ; 24)$ & $<0.0001$ & 56 & $(46 ; 65)$ & $<0.0001$ \\
\hline Maternal smoking (yes-no) & -1 & $(-10 ; 8)$ & 0.80 & -46 & $(-54 ;-37)$ & $<0.0001$ & -164 & $(-194 ;-133)$ & $<0.0001$ \\
\hline
\end{tabular}
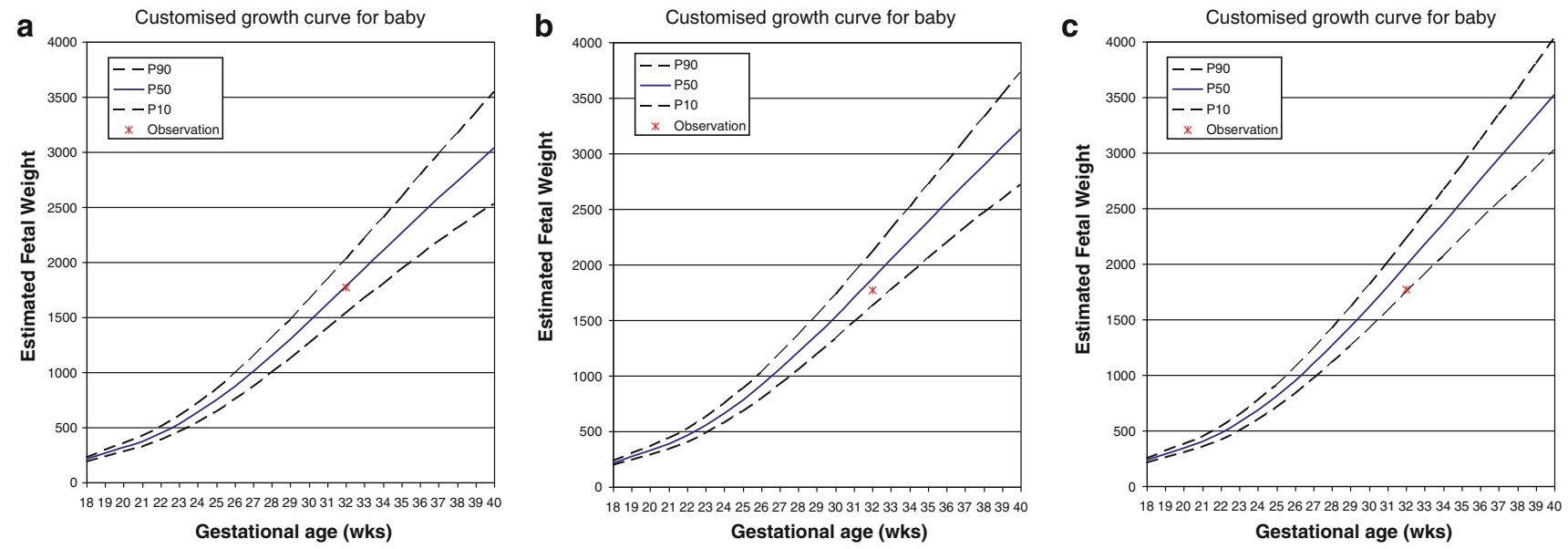

Fig. 2 Three different individually customised growth curves. (a) Customised growth curve for a child of a Surinamese Hindustanis nulliparous 30 year old woman, with a maternal height of $1.60 \mathrm{~m}$ and weight of $55 \mathrm{~kg}$ (b) Customised growth curve for a child of a Dutch

\section{Methodological considerations}

One of the strengths of this study was the prospective data collection from early pregnancy onwards. We had a large nulliparous 28 year old woman, with a maternal height of $1.67 \mathrm{~m}$ and weight of $65 \mathrm{~kg}$ (c) Customised growth curve for a child of a Moroccan multiparous 35 year old woman, with a maternal height of $1.75 \mathrm{~m}$ and weight of $85 \mathrm{~kg}$

sample size of 8,162 pregnant women and 16,018 estimated fetal weight measurements. In total, 5,473 pregnant women had complete information about all determinants. Women with non-complete information tended to be 


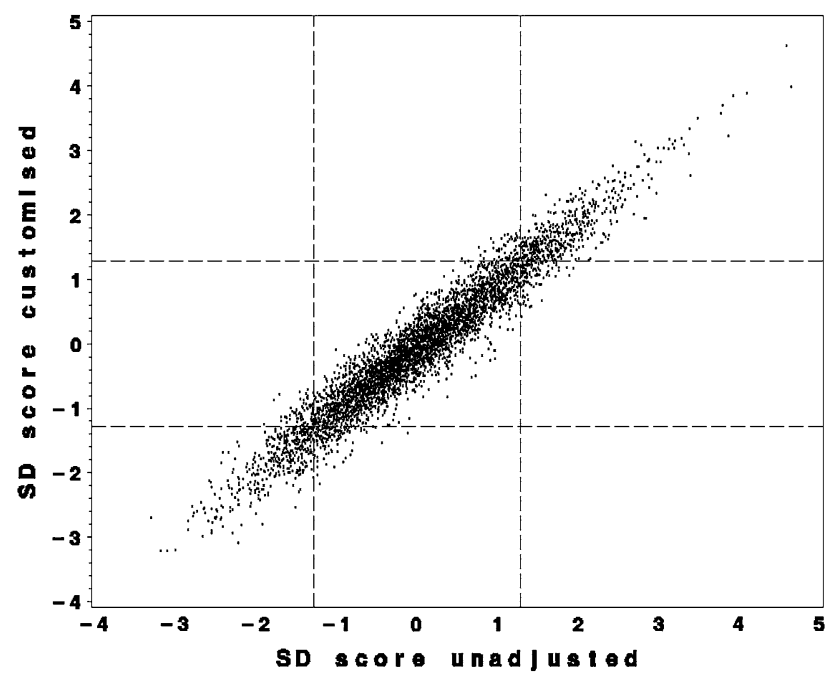

Fig. 3 Unadjusted reference and individually customised references. Relation between SD score obtained by the unadjusted reference ( $\mathrm{x}-$ axis) and by individually customised references (y-axis). Reference lines are drawn at P10 and P90. Standard deviation (SD) scores were computed by taking the difference between an observed and a predicted estimated fetal weight, divided by the residual SD corresponding to the gestational age. The various predictions using both methods lead to various SD scores and, in consequence, to different classifications of the fetus as "too small" (SD score $<1.28=$ P10) or "appropriate"

slightly younger, had slightly higher body mass index levels, were more frequently lower educated and were more frequently of non-European descent. Our study cohort comprised contemporary urban women, including about $40 \%$ from ethnic minorities in the Netherlands. The largest ethnic minority groups in this population were those from Turkish, Moroccan and Surinamese ancestry. The response rate at baseline for participation in the study was $61 \%$. The percentages of women from ethnic minority groups and lower socio-economic status were slightly lower than expected from the population figures in Rotterdam [27]. This might indicate a selection towards a relatively healthy population and might affect the generalizibility of our results. However, it is unlikely that non response has led to biased estimates, because biased estimates in large cohort studies mainly arise from loss to follow-up rather than from non-response at baseline [28]. Pregnancy dating was performed using ultrasound measurements of crown rump length or biparietal diameter at the first visit. This method might be better than dating by last menstrual period [5, 16-18]. However, this procedure neglects variation in early fetal growth. This might have caused an underestimation of the effects of the determinants on fetal weight in early pregnancy. This bias is expected to be small when pregnancy dating is performed in early pregnancy. Therefore, we excluded women who were enrolled and dated later than at a gestational age of 24 weeks. Finally, information on some determinants in this study was self-reported, which may have resulted in some underreporting and misclassification of certain adverse lifestyle related determinants. For example, selective underreporting of prepregnancy weight and maternal smoking would probably lead to smaller effect estimates for these variables.

Individually customised fetal weight charts

Many studies, of which several from the same cohort, have shown that non-pathological maternal and fetal characteristics might influence fetal growth [7, 29-32]. Physiological, or non-pathological maternal and fetal characteristics influence the fetal growth potential. They should therefore be considered when evaluating fetal growth. To the best of our knowledge, this is the first large population based cohort study that constructed individually customised fetal weight charts derived from prospectively collected ultrasound measurements. Gardosi et al. developed a model based on birth weight and assumed that the influence of maternal and fetal characteristics was proportional throughout pregnancy [12]. The maternal and fetal characteristics included in their model were selected on their influence on birth weight and included maternal height and weight, ethnic origin, parity and fetal sex [12]. After calculation of the "term optimal weight" for an individual child, an individually based fetus-specific intra-uterine growth chart for estimated fetal weight can be constructed using a proportionality equation linking estimated fetal weight during gestation to birth weight. Thus, another important assumption for their approach is that this proportionality equation is correct for each fetus. When we applied the model of Gardosi to our data, we observed larger effects of the determinants on estimated fetal weight as compared to our model. The model of Gardosi may overestimate the effect of maternal height, weight, ethnic origin, parity and fetal sex as it does not consider their disproportional effect during pregnancy. Also, part of the effects of maternal weight and parity during pregnancy on estimated fetal weight might be explained by maternal age, which is not included in the model of Gardosi, but was included in our model. Furthermore, differences in study populations might partly explain differences in effect estimates. As our model is based on estimated fetal weight derived from ultrasound measurements, we consider our individual customised charts as better applicable for fetal assessment than charts derived from birth weight data.

Johnsen et al. also developed a model for estimated fetal weight, including maternal and fetal characteristics [11]. This study used data of 634 women visiting a low-risk antenatal clinic and used ultrasound measurements to estimate fetal weight. They included fetal sex, fetal position, cephalic index, maternal age, maternal smoking and 
maternal height in their model, and did not include parity and maternal weight as they had no significant effect on estimated fetal weight. The differences with our model might be due to differences in the study population, differences in sample size and methodological issues. The model of Johnsen et al. did not include interactions of the maternal characteristics with gestational age, which is important, as we and other studies have shown that the effect of maternal characteristics differs during pregnancy. Pang et al. developed customised models for biparietal diameter, head circumference, abdominal circumference and femur length, separately, but not for estimated fetal weight [9]. Their study was based on 533 subjects. In line with our results, they observed significant effects of similar maternal and fetal characteristics on in utero fetal biometry between 24 and 40 weeks of gestation.

Our results suggest that classification of individual children as born with a small size for gestational age may be different between normal population charts and individually customised charts. Our findings support the suggested concept of customising fetal growth charts $[6,9$, 11]. Use of individually customised fetal growth charts enable identification of pathological smallness instead of constitutional small size and can prevent unnecessary classification as small size for gestational age. Some previous studies suggested that there is no additional benefit of using customised fetal growth charts. A study among 9,526 US women compared perinatal outcomes among small for gestational age fetuses using ultrasound references and individualised references of Gardosi and observed similar risks of adverse outcomes among fetuses classified by both references [33]. Another study that examined the value of customised birth weight percentiles in a simulated cohort, showed that maternal characteristics added very little information to the identification of intra-uterine growth retardation [34]. Therefore, further studies are needed to evaluate the use of individually customised fetal growth charts, especially focused on prediction on perinatal outcomes.

\section{Conclusion}

We developed a model to construct individually customised fetal growth charts, taking non-pathological maternal and fetal characteristics and their increasing effect during pregnancy into consideration. With these customised growth charts, fetal size can be evaluated taking the normal variation in fetal growth potential into account. These charts might be useful for use in epidemiological studies and in clinical practice. Further studies are needed to validate our model and to examine whether and to what extend the use of customised growth charts can improve identification of children that are at risk for morbidity in the perinatal period and later in life.

Acknowledgments The Generation R Study is conducted by the Erasmus Medical Center in close collaboration with the School of Law and Faculty of Social Sciences of the Erasmus University Rotterdam, the Municipal Health Service Rotterdam area, Rotterdam, the Rotterdam Homecare Foundation, Rotterdam and the Stichting Trombosedienst and Artsenlaboratorium Rijnmond (STAR-MDC), Rotterdam. We gratefully acknowledge the contribution of children and parents, general practitioners, hospitals, midwives and pharmacies in Rotterdam. The general design of Generation R Study is made possible by financial support from the Erasmus Medical Center, Rotterdam, the Erasmus University Rotterdam, the Netherlands Organization for Health Research and Development (ZonMw), the Netherlands Organisation for Scientific Research (NWO), the Ministry of Health, Welfare and Sport and the Ministry of Youth and Families. Vincent Jaddoe received additional grants from the Netherlands Organization for Health Research and Development (ZonMw 90700303, 916.10159).

Conflict of interest The authors declare that they have no conflict of interest.

Open Access This article is distributed under the terms of the Creative Commons Attribution Noncommercial License which permits any noncommercial use, distribution, and reproduction in any medium, provided the original author(s) and source are credited.

\section{References}

1. Fang S. Management of preterm infants with intrauterine growth restriction. Early Hum Dev. 2005;81:889-900.

2. Pallotto EK, Kilbride HW. Perinatal outcome and later implications of intrauterine growth restriction. Clin Obstet Gynecol. 2006;49:257-69.

3. Geelhoed JJ, Jaddoe VW. Early influences on cardiovascular and renal development. Eur J Epidemiol. 2010;25:677-92.

4. Osler M, Lund R, Kriegbaum M, Andersen AM. The influence of birth weight and body mass in early adulthood on early coronary heart disease risk among Danish men born in 1953. Eur J Epidemiol. 2009;24:57-61.

5. Verburg BO, Steegers EA, De Ridder M, Snijders RJ, Smith E, Hofman A, et al. New charts for ultrasound dating of pregnancy and assessment of fetal growth: longitudinal data from a population-based cohort study. Ultrasound Obstet Gynecol. 2008;31:388-96.

6. Gardosi J, Mongelli M, Wilcox M, Chang A. An adjustable fetal weight standard. Ultrasound Obstet Gynecol. 1995;6:168-74.

7. Jacquemyn Y, Sys SU, Verdonk P. Fetal biometry in different ethnic groups. Early Hum Dev. 2000;57:1-13.

8. Mongelli M, Gardosi J. Longitudinal study of fetal growth in subgroups of a low-risk population. Ultrasound Obstet Gynecol. 1995;6:340-4.

9. Pang MW, Leung TN, Sahota DS, Lau TK, Chang AM. Customizing fetal biometric charts. Ultrasound Obstet Gynecol. 2003;22:271-6.

10. Schwarzler P, Bland JM, Holden D, Campbell S, Ville Y. Sexspecific antenatal reference growth charts for uncomplicated singleton pregnancies at 15-40 weeks of gestation. Ultrasound Obstet Gynecol. 2004;23:23-9. 
11. Johnsen SL, Rasmussen S, Wilsgaard T, Sollien R, Kiserud T. Longitudinal reference ranges for estimated fetal weight. Acta Obstet Gynecol Scand. 2006;85:286-97.

12. Gardosi J, Francis A. Customised antenatal growth chartsGROW-chart. 7.1 ed. Gestation network. www.gestation.net. 2006.

13. Mongelli M, Gardosi J. Reduction of false-positive diagnosis of fetal growth restriction by application of customized fetal growth standards. Obstet Gynecol. 1996;88:844-8.

14. Jaddoe VW, van Duijn CM, van der Heijden AJ, Mackenbach JP, Moll HA, Steegers EA, et al. The Generation R Study: design and cohort update 2010. Eur J Epidemiol. 2010;25:823-41.

15. World Medical Association Inc. Declaration of Helsinki. Ethical principles for medical research involving human subjects. J Indian Med Assoc. 2009;107:403-5.

16. Campbell S, Warsof SL, Little D, Cooper DJ. Routine ultrasound screening for the prediction of gestational age. Obstet Gynecol. 1985;65:613-20.

17. Taipale P, Hiilesmaa V. Predicting delivery date by ultrasound and last menstrual period in early gestation. Obstet Gynecol. 2001;97:189-94.

18. Tunon K, Eik-Nes SH, Grottum P. A comparison between ultrasound and a reliable last menstrual period as predictors of the day of delivery in 15, 000 examinations. Ultrasound Obstet Gynecol. 1996;8:178-85.

19. Hadlock FP, Deter RL, Harrist RB, Park SK. Fetal abdominal circumference as a predictor of menstrual age. AJR Am J Roentgenol. 1982;139:367-70.

20. Hadlock FP, Harrist RB, Deter RL, Park SK. Fetal femur length as a predictor of menstrual age: sonographically measured. AJR Am J Roentgenol. 1982;138:875-8.

21. Shepard M, Filly RA. A standardized plane for biparietal diameter measurement. J Ultrasound Med. 1982;1:145-50.

22. Hadlock FP, Harrist RB, Sharman RS, Deter RL, Park SK. Estimation of fetal weight with the use of head, body, and femur measurements-a prospective study. Am J Obstet Gynecol. 1985;151:333-7.

23. Statistics Netherlands. Allochtonen in Nederland. Voorburg/ Heerlen2004.
24. Jaddoe VW, Verburg BO, de Ridder M, Hofman A, Mackenbach JP, Moll HA, et al. Maternal smoking and fetal growth characteristics in different periods of pregnancy: the Generation $\mathrm{R}$ Study. Am J Epidemiol. 2007;165:1207-15.

25. Bernstein IM, Plociennik K, Stahle S, Badger GJ, Secker-Walker R. Impact of maternal cigarette smoking on fetal growth and body composition. Am J Obstet Gynecol. 2000;183:883-6.

26. Royston P, Ambler G, Sauerbrei W. The use of fractional polynomials to model continuous risk variables in epidemiology. Int $\mathrm{J}$ Epidemiol. 1999;28:964-74.

27. Centre for Research and Statistics RC. http://www.cos.rotterdam. nl. 2005.

28. Nohr EA, Frydenberg M, Henriksen TB, Olsen J. Does low participation in cohort studies induce bias? Epidemiology. 2006;17:413-8.

29. Bakker R, Steegers EA, Biharie AA, Mackenbach JP, Hofman A, Jaddoe VW. Explaining differences in birth outcomes in relation to maternal age: the Generation R Study. Bjog. 2011;118:500-9.

30. Ay L, Kruithof CJ, Bakker R, Steegers EA, Witteman JC, Moll HA, et al. Maternal anthropometrics are associated with fetal size in different periods of pregnancy and at birth. The Generation $\mathrm{R}$ Study. Bjog. 2009;116:953-63.

31. Drooger JC, Troe JW, Borsboom GJ, Hofman A, Mackenbach JP, Moll HA, et al. Ethnic differences in prenatal growth and the association with maternal and fetal characteristics. Ultrasound Obstet Gynecol. 2005;26:115-22.

32. Albouy-Llaty M, Thiebaugeorges O, Goua V, Magnin G, Schweitzer M, Forhan A et al. Influence of fetal and parental factors on intra-uterine growth measurements: results of the EDEN mother-child cohort. Ultrasound Obstet Gynecol. 2011. doi: 10.1002/uog.9006.

33. Zhang J, Mikolajczyk R, Grewal J, Neta G, Klebanoff M. Prenatal application of the individualized fetal growth reference. Am J Epidemiol. 2011;173:539-43.

34. Hutcheon JA, Walker M, Platt RW. Assessing the value of customized birth weight percentiles. Am J Epidemiol. 2011;173:459-67. 